\title{
Optic nerve sheath meningocele
}

This article was published in the following Dove Press journal: International Medical Case Reports Journal

\author{
Musleh Algarni ${ }^{1,2}$ \\ Pejman J Maralani ${ }^{3}$ \\ Arun NE Sundaram' \\ 'Department of Ophthalmology \\ and Vision Sciences, Sunnybrook \\ Health Sciences Center, University \\ of Toronto, Toronto, ON, Canada; \\ 2Department of Medicine, Al Thagher \\ General Hospital, Jeddah, Saudi Arabia; \\ ${ }^{3}$ Department of Medical Imaging, \\ Sunnybrook Health Sciences Center, \\ University of Toronto, Toronto, ON, \\ Canada
}

Correspondence: Arun NE Sundaram Department of Medical Imaging, Sunnybrook Health Sciences Center, University of Toronto, 2075 Bayview Avenue, MI 202c, Toronto, ON, M4N 3M5, Canada

Email Arun.Sundaram@sunnybrook.ca

\begin{abstract}
Optic nerve sheath meningocele, also called dural ectasia of the optic nerve, is a benign dilation of the optic nerve sheath. We report two interesting cases of primary optic nerve sheath meningocele. Etiology, clinical features, and management options are discussed. Keywords: optic nerve sheath meningocele, dural ectasia of the optic nerve sheath, optic disc edema
\end{abstract}

\section{Introduction}

Primary dilatation of the optic nerve sheath is a rare clinicoradiological entity. Garrity et al proposed the term "optic nerve sheath meningocele" to describe such a condition. ${ }^{1}$ Optic nerve sheath enlargement can be seen in cases of orbital apex mass lesions such as meningiomas or gliomas of the optic nerve, neurofibromatosis type I, or idiopathic intracranial hypertension. ${ }^{2,3}$ We report two cases of primary dilatation of the optic nerve sheath without an associated pathology.

\section{Case I}

An 82-year-old man presented with blurred vision and a pressure-like sensation in the left eye for a duration of 1 year. He had a past medical history of hypertension, glaucoma, and prostate cancer. His best corrected visual acuity was 20/20 in both eyes. He was able to read all Ishihara plates with both eyes. His pupils measured $3 \mathrm{~mm}$ on both sides. He had a grade one relative afferent pupillary defect in his left eye. The left optic disc showed mildly elevated and indistinct nasal margins. The blood vessels over the left disc were not obscured, and there were no hemorrhages or exudates. A subtle macular edema, a few choroidal folds, and tortuous retinal vessels were seen in the left eye. The right optic disc was normal. The reminder of the neuroophthalmic examination was normal. There were no cutaneous lesions suggestive of neurofibromatosis. A central 24-2 threshold Humphrey visual field was normal in both sides. Macular optical coherence tomography showed retinal thickening between the optic nerve head and fovea.

Lumbar puncture was performed. Cerebrospinal fluid (CSF) opening pressure was $90 \mathrm{~mm} \mathrm{H}_{2} \mathrm{O}$. CSF cell count and biochemistry were normal, and cytology was negative for malignant cells. Magnetic resonance imaging (MRI) of the brain and orbits showed enlarged CSF spaces around the normal appearing left optic nerve (Figure 1). There was no abnormal enhancement of the optic nerve or its sheath. Brain images 
demonstrated only age-related volume loss. During follow-up visits at 4 and 9 months, his vision remained stable.

\section{Case 2}

A 53-year-old woman was referred for an incidental swollen left optic disc. She had a past medical history of chronic renal failure secondary to polycystic kidney disease requiring regular hemodialysis, hypertension, and atrial fibrillation. She had no visual symptoms or headache with the best corrected visual acuity of 20/30 in the right eye and 20/25 in the left eye. Color vision was normal in both eyes. There was no relative afferent pupillary defect. Optic disc margins were indistinct bilaterally. The rest of the neuroophthalmic examination was normal.

MRI of the orbits (Figure 2) showed bilateral tortuous optic nerves with prominent CSF spaces around them. CSF opening pressure was $200 \mathrm{~mm} \mathrm{H}_{2} \mathrm{O}$. CSF constituents were all normal except for elevated protein of $1,075 \mathrm{mg} / \mathrm{L}$ (normal range $150-450 \mathrm{mg} / \mathrm{L}$ ), which was likely caused by chronic uremia.

\section{Discussion}

Primary dilatation of the optic nerve sheath was first described by Bane in 1918. He called it cyst of the dural sheath of optic nerve. ${ }^{4}$ Other names have been used over the years to describe similar cases such as "optic hydrops", 5 "ascites of the optic nerve", 6 "patulous subarachnoid space", 7 "arachnoid cyst", "optic nerve sheath enlargement", 9 and "dural ectasia of the optic nerve". ${ }^{2}$ Garrity et al coined the term "optic nerve sheath meningocele". 1,10

There are no pathognomonic symptoms of optic nerve sheath meningocele, though nonspecific, blurred vision, and retrobulbar pressure are common presenting symptoms. A subset of patients develop progressive hyperopia and choroidal folds. ${ }^{1,11}$ The optic disc can vary in appearance from edematous to a pale disc. ${ }^{1}$ Cystoid macular edema has also been reported. ${ }^{12}$ Other signs of optic nerve dysfunction can be present too. Our patient in case 1 who is the oldest patient to be reported with this condition so far had transient macular edema, which resolved spontaneously. He also had a mild swelling of the optic disc whereas the patient in case 2 had no symptoms and was incidentally discovered to have optic disc swelling which eventually led to the diagnosis.

Dilatation of the optic nerve sheath can be secondary to orbital mass lesion and has been reported in neurofibromatosis and idiopathic intracranial hypertension. ${ }^{2,3}$ The mechanism behind the development of optic nerve sheath dilation in such cases is not clear.

The diagnosis is usually made by obtaining MRI of the orbits. The dilated optic nerve sheath which is filled with CSF can easily be visualized. Coronal T2-weighed images can show the so-called bull's eye appearance, which represents expanded CSF spaces around the optic nerve. ${ }^{1} \mathrm{MRI}$ is
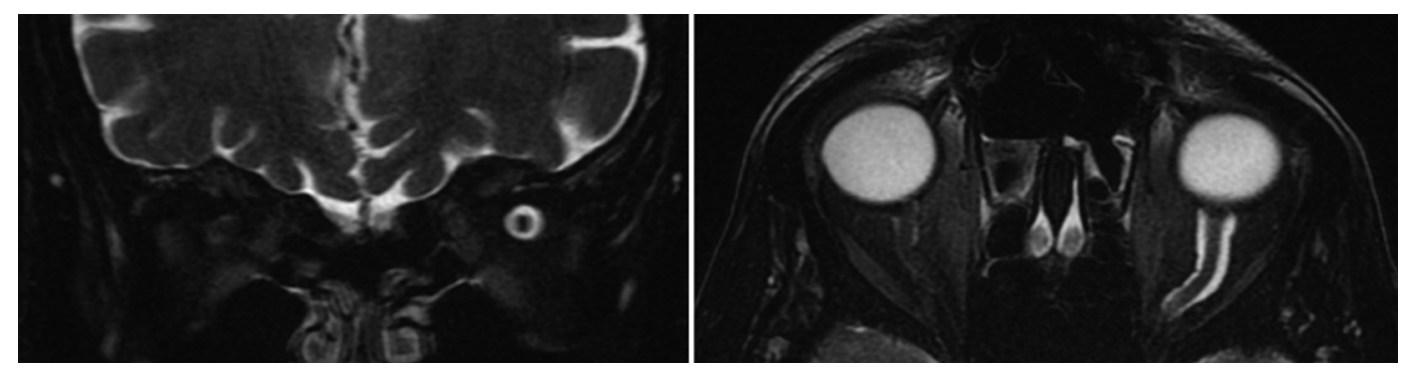

Figure I Axial (left) and coronal (right) fat-suppressed T2-weighted images of the orbits demonstrate enlarged CSF spaces around the normal appearing left optic nerve. Abbreviation: CSF, cerebrospinal fluid.
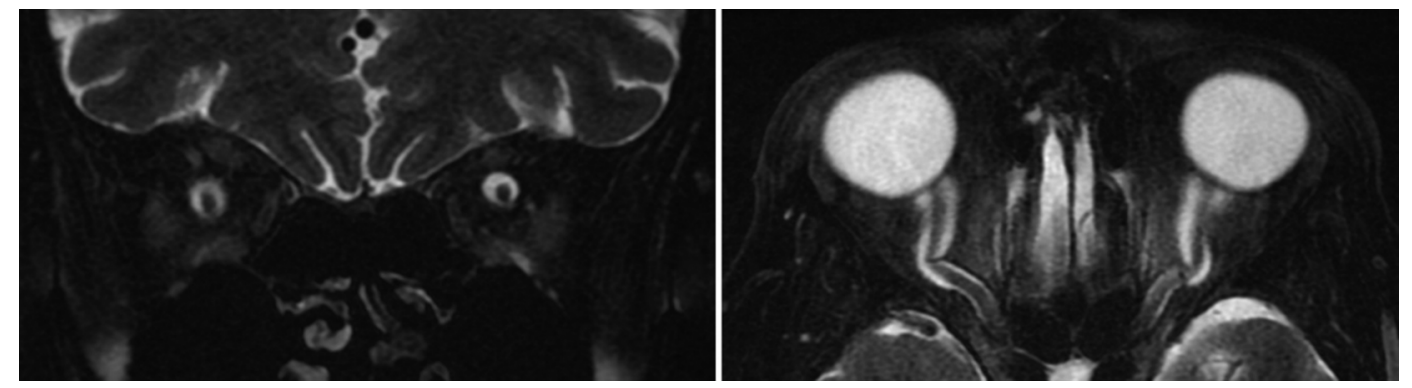

Figure 2 Axial (left) and coronal (right) fat-suppressed T2-weighted images of the orbits demonstrate enlarged CSF spaces around bilateral normal appearing optic nerve. Abbreviation: CSF, cerebrospinal fluid. 
also useful to rule out conditions that can lead to secondary enlargement of optic nerve sheath such as orbital masses and gliomas. It is imperative to determine CSF opening pressure to exclude idiopathic intracranial hypertension.

The prognosis for this condition varies. Progressive visual loss can occasionally be seen. Treatment is usually tailored to the patient's vision. Carbonic anhydrase inhibitors can be beneficial in some cases. Surgical interventions in the form of optic nerve sheath fenestration may be of benefit in situations where there is progressive vision loss. In a review of literature of 33 patients with optic nerve sheath meningocele, 13 patients underwent surgical treatment. Five of the 13 patients who had the procedure experienced improvement of their symptoms while 6 had no change in their symptoms. ${ }^{13}$

In summary, optic nerve sheath meningocele refers to dilatation of the optic nerve sheath, which can have varying presentation. Optic nerve dysfunction can be seen, and it can range in severity from subtle involvement to a progressive vision loss. The diagnosis is usually made with MRI of the orbits. Optic nerve sheath fenestration may be an option in patients with progressive vision loss.

\section{Disclosure}

The authors report no conflicts of interest in this work.

\section{References}

1. Garrity JA, Trautmann JC, Bartley GB, et al. Optic nerve sheath meningoceles. Clinical and radiographic features in 13 cases with a review of the literature. Ophthalmology. 1990;97(11):1519-1531.

2. Lövblad KO, Remonda L, Ozdoba C, Huber P, Schroth G. Dural ectasia of the optic nerve sheath in neurofibromatosis type 1: CT and MR features. J Comput Assist Tomogr. 1994;18(5):728-730.

3. Agid R, Farb RI, Willinsky RA, Mikulis DJ, Tomlinson G. Idiopathic intracranial hypertension: the validity of cross-sectional neuroimaging signs. Neuroradiology. 2006;48(8):521-527.

4. Bane WC. Cyst of dural sheath of optic nerve. Am J Ophthalmol. 1918;1(1):17.

5. Jinkins JR. Optic hydrops: isolated nerve sheath dilation demonstrated by CT. AJNR Am J Neuroradiol. 1987;8(5):867-870.

6. Haag JR, Smith JL, Susac JO, Byrne SF. Optic atrophy following jejunoileal bypass. J Clin Neuroophthalmol. 1985;5(1):9-15.

7. Rothfus WE, Curtin HD, Slamovits TL, Kennerdell JS. Optic nerve/ sheath enlargement. A differential approach based on high-resolution CT morphology. Radiology. 1984;150(2):409-415.

8. Miller NR, Green WR. Arachnoid cysts involving a portion of the intraorbital optic nerve. Arch Ophthalmol. 1975;93(11):1117-1121.

9. Wojno T, Beck RW, Grosserode R. Bilateral optic nerve sheath enlargement. Ophthalmic Surg. 1986;17(9):584-588.

10. Mesa-Gutiérrez JC, Quiñones SM, Ginebreda JA. Optic nerve sheath meningocele. Clin Ophthalmol. 2008;2(3):661-664.

11. Dailey RA, Mills RP, Stimac GK, Shults WT, Kalina RE. The natural history and CT appearance of acquired hyperopia with choroidal folds. Ophthalmology. 1986;93(10):1336-1342.

12. Shanmuganathan V, Leatherbarrow B, Ansons A, Laitt R. Bilateral idopathic optic nerve sheath meningocele associated with unilateral transient cystoid macular oedema. Eye. 2002;16(6):800-802.

13. Lunardi P, Farah JO, Ruggeri A, et al. Surgically verified case of optic sheath nerve meningocele: case report with review of the literature. Neurosurg Rev. 1997;20(3):201-205.
International Medical Case Reports Journal

\section{Publish your work in this journal}

The International Medical Case Reports Journal is an international, peer-reviewed open-access journal publishing original case reports from all medical specialties. Previously unpublished medical posters are also accepted relating to any area of clinical or preclinical science. Submissions should not normally exceed 2,000 words or

\section{Dovepress}

4 published pages including figures, diagrams and references. The manuscript management system is completely online and includes a very quick and fair peer-review system, which is all easy to use. Visit $\mathrm{http}: / /$ www.dovepress.com/testimonials.php to read real quotes from published authors. 